Sādhanā Vol. 40, Part 6, September 2015, pp. 1899-1911. (C) Indian Academy of Sciences

\title{
The effect of manufacturing tolerances on the load carrying capacity of large diameter bearings
}

\author{
STARVIN M $\mathrm{S}^{1, *}$ and MANISEKAR $\mathrm{K}^{2}$ \\ ${ }^{1}$ Department of Mechanical Engineering, Anna University Tirunelveli Region, \\ Tirunelveli, Tamilnadu 627007, India \\ ${ }^{2}$ Centre for Manufacturing Sciences National Engineering College, \\ Kovilpatti 628503, India \\ e-mail: mstarvin@gmail.com
}

MS received 8 November 2013; revised 19 March 2015; accepted 10 July 2015

\begin{abstract}
This paper deals with simplified 3D finite element (FE) analysis on the effect of manufacturing tolerances on the load carrying capacity of large diameter bearings based on Hertz theory. The nonlinear connector elements are used to model the rolling elements. This model enables us to evaluate the contact load on the rolling elements with relatively reduced calculation time. FE study has been carried out by allocating tolerance on balls and raceways using Monte Carlo simulation technique. The variation in dimension on balls is taken as per IS 2898-1976. A coding has been developed and employed for Monte Carlo simulation. Using the results of Monte Carlo simulation, tolerance has been assigned to the elements of large diameter bearing. From the results of finite element analysis, it is identified that analysis of large diameter bearing with tolerance on ball and raceway will lead to safe design.
\end{abstract}

Keywords. Slewing bearing; Hertz theory; load distribution; nonlinear connector elements; tolerance.

\section{Introduction}

A slewing bearing is basically a large-sized bearing which may also have gear teeth to receive the energy of a motor, in accordance with the desired application. The field of application of this kind of bearing is very varied. It can be used in tower cranes, wind-power generators, excavation machinery and capital goods machinery, etc. (Jose Ignacio Amasorrain 2003). These bearings possess a number of characteristic features that differentiate them from commonly used rolling bearings. The functional quality of such a machine component is heavily dependent upon one or two critical dimensions of the assembly. For example, the quality of a ball bearing is based on the clearance between the balls and the inner or outer racings. These critical dimensions result from the cumulative effect of two or more functional dimensions. Bearing dimensions must be

*For correspondence 
toleranced to allow for the limits in accuracy of the machining process and measurement techniques. The resulting small variation in dimensions, altering the shape and size of the clearance space, can have a significant effect on the performance of bearings. Tolerance analysis has to be conducted to identify the functional dimensions that are affecting a critical dimension. Once the functional dimensions are identified, then the tolerances for these dimensions are to be allocated from the critical dimension tolerance. Thus the tolerance design of a product consists of tolerance analysis and tolerance allocation (Hong-Chao Zhang 1997). Dimensional tolerancing is designed to ensure that products produced will meet the designed requirements namely functionality, minimum cost and maximum interchangeability (Ngoi et al 2000).

The main criterion for the choice of slewing ring bearings is based on their static load carrying capacity. The slewing bearings are fastened using an assembly of bolts to the body of the supporting machine, which are also subjected to significant load. This has an important effect on the load acting on the rolling elements as well as on the load carrying capacity of the bearing. Due to this reason, it is necessary to apply more precise methods for the design of bearings. These include the effect of supporting structures deformation and tolerances on the load carrying capacity of the bearings. Analysis of large diameter bearing is a complex one because of the high nonlinearity involved in the process and the analytical solutions need massive simplifications. In such a case, Finite element methods are widely used to solve the problems. Zupan \& Prebil (2001) estimate the influence of geometrical and stiffness parameters on the calculation of the load carrying capacity. FEM does not remove all difficulties appearing in slew bearing computation. Smolnicki (1999) used FEM for modeling slew bearings. Proper modeling of rolling element is the key factor while solving the problem.

Modeling of large number of rolling elements (several dozen or more), the shape of the rolling elements and the modeling of the contact problem in a full bearing makes it practically very difficult. Considering the complexity of interactions and in order to obtain a cost-effective solution, one should apply a revolutionary approach like substructuring technique, which applies a super element in the global model to replace subassemblies. In this particular model, rolling elements were replaced with nonlinear traction springs. This type of a simplification allows avoiding the multiple modeling of the contact problem, but it introduces the requirement of specifying nonlinear load-deformation characteristics of the nonlinear traction springs, which is modeling the rolling elements: a similar solution in rolling bearing models was used by Smolnicki \& Rusiniski (2007). A 'superelement' consisting of two beam elements with high stiffness joined by truss element and contact element was used. Goncz et al (2013) developed a computational model to determine the dynamic load capacity of large three-row roller slewing bearing by considering the effect of clearances using three-dimensional FE techniques. However, literature is very scarce on the effect of tolerance in the design of large diameter bearing. The large diameter bearings are used in different applications in which the collapse of a bearing could lead to enormous economic damage and potential disastrous consequences for the users (e.g. Nuclear Reactor, Cranes and Wind mill) and it requires close tolerance owing to its applications. It is therefore understandable that it is inevitable to consider the effect of tolerance in the design of large diameter bearing. Extensive experimental analysis on large diameter bearings is practically impossible because of high costs. Hence the objective of the present work is to find the effect of dimensional variation of rolling elements and groove radius of raceways in the load carrying capacity of large diameter bearing using finite element analysis.

In order to accomplish the objective, in this paper a three-dimensional model of a large diameter bearing had been developed. The developed finite element model is validated. In the 3D model, the connector elements are used in place of rolling elements i.e. ball. This has two 
advantages viz. complexity of the model is reduced and computational time for solving the problem reduces considerably. Using Hertz theory, the stiffness characteristics of connector elements were found. The same had also been found using the finite element method and also experimentally. The tolerance allocation on the ball is done based on IS 2898-1976 using Monte Carlo techniques. Using this proposed model, effort has been made to identify the effect of dimensional variation in the load carrying capacity of large diameter bearing.

\section{Geometrical study of large diameter angular contact slewing ring bearings}

The geometrical study of large diameter bearings is made from previous works to identify a contact model applicable to large diameter or slewing ring ball bearings and which can be easily implemented in the definition of a nonlinear element in the simplified FEM. In this context, models given by the Hertz theory can be used to model the contact between the raceways and the rolling elements due to the fact that many studies highlight nonlinear behavior in terms of displacement under loading. By using this theory, one can establish the dimensions of the contact areas and the relative distance between two rings. Also, Liao \& Lin (2001) analytically identified an effective elastic modulus of contact in the bearing system from the radii of curvature of the raceways by using dimensionless parameters. A similar approach, which is based on Houpert's works (Houpert 2001) for line and point contacts, was used by Antoine et al (2006). Consequently, it can be concluded that the geometrical parameters in a slewing bearing, such as the dimensions and the flatness of the contact areas, the radius of curvature, and physical conditions such as the friction-free contact are sufficient criteria for the Hertzian contact to be considered.

The Hertzian parameters can be obtained by the following relations to study the global-local approach for large diameter slewing ring bearing. The contact area parameters a and $\mathrm{b}$ (in $\mathrm{mm}$ ) are given respectively by the following relations:

$$
\begin{gathered}
a=1.71 \times 10^{-2}(1-S)^{-0.4091}\left(D_{w}\right)^{1 / 3}\left(1 \pm \frac{D_{w} \cos \beta}{D_{\text {mean }}}\right)^{-0.0758} Q^{1 / 3} \\
b=1.52 \times 10^{-2}(1-S)^{0.1974}\left(D_{w}\right)^{1 / 3}\left(1 \pm \frac{D_{w} \cos \beta}{D_{\text {mean }}}\right)^{0.5307} Q^{1 / 3}
\end{gathered}
$$

The maximum contact pressure $(\mathrm{MPa})$ for a point contact can be calculated by using the following equation:

$$
\begin{gathered}
P_{\max }=1.84 \times 10^{3}(1-S)^{0.2117}\left(1 \pm \frac{D_{W} \cos \beta}{D_{\text {mean }}}\right)^{-0.4550} \frac{Q^{1 / 3}}{D_{w}^{2 / 3}} \\
P_{\text {mean }}=\frac{P_{\max }}{1.5} .
\end{gathered}
$$

By using the method presented and the above relationships, one can check that the mean pressure times the contact area is equal to the applied load Q. Results relative to the study are present in table 1.

\section{General approach}

The key principle of this method is the replacement of the rolling elements under compression by nonlinear traction springs or nonlinear connector elements (in ABAQUS Standard) between the centers of curvature (Houpert 2001). Consequently, rolling elements under compression are 
Table 1. Calculation of Hertzian parameters for rigid rings.

\begin{tabular}{|c|c|c|}
\hline Contact angle $\beta^{\circ}$ & & $60^{\circ}$ \\
\hline Number of rolling elements, Z & & 70 \\
\hline Rolling element size, $\mathrm{D}_{\mathrm{w}}(\mathrm{mm})$ & & 31.75 \\
\hline Conformity ratio $f_{\mathrm{i}} / f_{\mathrm{o}}$ & & 0.52 \\
\hline Osculation factor & & 0.962 \\
\hline \multirow{2}{*}{ Contact area dimensions at inner race contact } & $\mathrm{a}_{\mathrm{i}}(\mathrm{mm})$ & 5.69 \\
\hline & $b_{i}(\mathrm{~mm})$ & 0.7026 \\
\hline \multirow[t]{2}{*}{ Contact area dimensions at outer race contact } & $\mathrm{a}_{\mathrm{o}}(\mathrm{mm})$ & 5.689 \\
\hline & $\mathrm{b}_{0}(\mathrm{~mm})$ & 0.703 \\
\hline Maximum contact pressure $\mathrm{N} / \mathrm{mm}^{2}$ & & 2544.774 \\
\hline Mean contact pressure $\mathrm{N} / \mathrm{mm}^{2}$ & & 1696.516 \\
\hline
\end{tabular}

modeled by nonlinear connector element working only in tension. This is physically and geometrically justified, since under load, the raceways shift toward each other and thus simultaneously altering the distance between their centers of curvature and compressing the rolling elements figure 1.

By using this approach, it is possible to determine not only the equivalent contact load, but also the variation in the contact angle from the displacement of the curvature centers. A rolling element in a sector is defined by two nodes representing the centers of curvature of the raceways. Each node is linked to the corresponding opposite node by nonlinear traction springs or connector element (figure 2). The two zones of contact between the rolling element and raceway in a sector are modeled by rigid shells and coupled by rigid beam elements to the corresponding centers of curvature at two nodes materializing the contact ellipse, as shown in figure 2 . It should be noted that local deformations, which are taken into account by the nonlinear connector elements or springs, should not be perturbed by further singular or numerical deformations. The rigid shell elements are added in order to minimize this risk, especially at the linkage zone of the rigid beams.

\section{Connector element definition}

The modeling of rolling elements by means of a connector element is a challenging task. The contact characteristics of the rolling element and the raceways have to be investigated carefully.

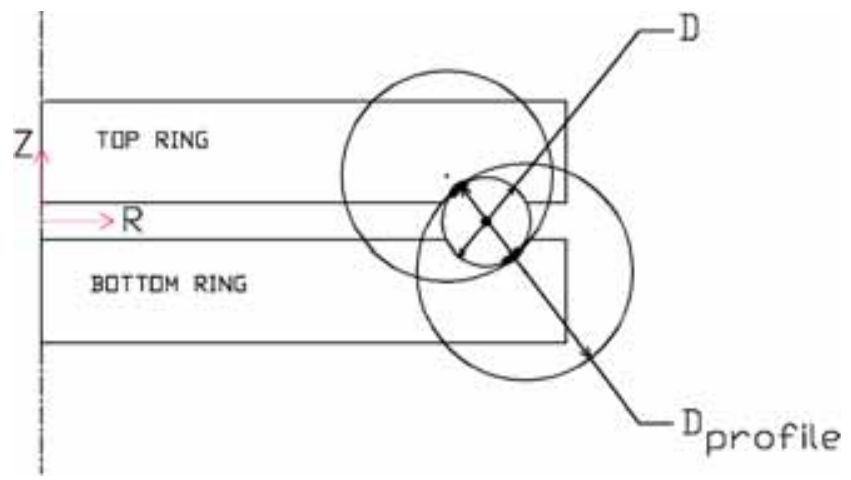

Figure 1. Geometry of angular (two point) contact. 


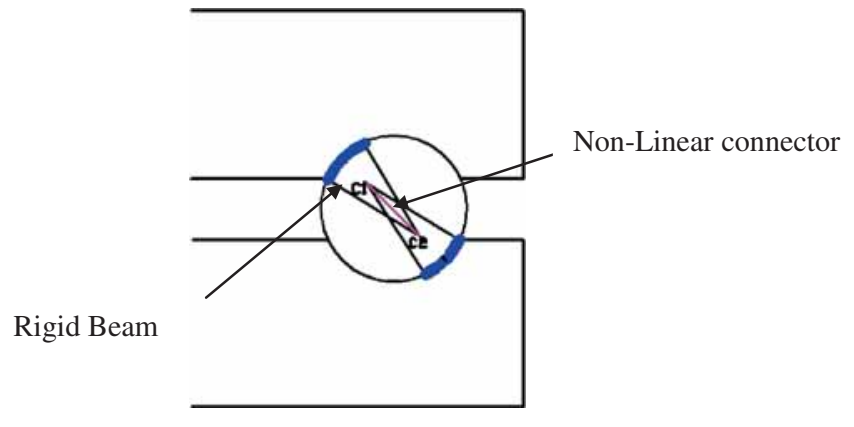

Figure 2. General approach.

In fact, ball deformations are mainly concentrated in the vicinity of the contact points. In this context, models given by the Hertz theory can be used to model the contact between the raceways and the rolling elements (Alain Daidie et al 2008). It can be mathematically modeled by the following equation:

$$
\delta=K Q^{1 / m}
$$

where $K$ is the flexibility of the rolling elements, $Q$ is the contact load in $N, \delta$ is the deflection in $\mathrm{mm}$, and $m$ is the Hertzian constant exponent ( $m=1.5$ for point contact).

However, the flexibility $K$ is a function of the osculation ratio $S$. Since the latter is an important industrial parameter for bearing manufacturers, it would be judicious to explicitly include its effect on the deflection relationship. In this framework, the analytical relationship given by Houpert (2001) can be used to analytically derive the osculation ratio on the deflection. This relationship is given by the following equation

$$
\delta=8.97 * 10^{-4}(1-s)^{0.1946} \frac{Q^{2 / 3}}{D_{W}^{1 / 3}} .
$$

The leading manufacturers of bearing SKF (Svenska Kullagerfabriken) and INA (Schaeffler Group) used the following relationship to find the deformation.

The SKF relationship for deformation

$$
\delta=\frac{4.5 \cdot 10^{-4}}{\sqrt[3]{D_{w}}} Q^{2 / 3},
$$

whereas the INA relationship for deformation

$$
\delta=\frac{4.84 \cdot 10^{-4}}{\sqrt[3]{D_{w}}} Q^{2 / 3} .
$$

The above relationships can be used to find the deformation of the rolling bearings. However, because of the highly intimate contact between the rolling element and the tracks and the material nonlinearity, it is most convenient to use the finite element method to determine the nonlinear force-deflection characteristic. 


\subsection{Numerical determination of stiffness}

The numerical rolling contact model (figure 3) was used to simulate a contact of the rolling element and a bearing raceway at a varying contact load from $1 \mathrm{kN}$ to $30 \mathrm{kN}$. The actual model is meshed with "C3D8R: an 8-node linear brick, reduced integration, hourglass control" element in Abaqus standard FE software (Starvin et al 2013). In the direct contact zone, the edges of the contact surface have been divided so as to obtain the dimensions of the segments of the contact surface of about $0.1 \times 0.1 \mathrm{~mm}$. (number of elements on the contact zone: 496, number of nodes in the contact zone: 638). Material properties were set for the model with Young modulus, $\mathrm{E}=210,000 \mathrm{~N} / \mathrm{mm}^{2}$, and Poisson's ratio, $v=0.3$. The calculation of the load-deformation characteristics of the contact zone of the ball raceway has been carried out using Hertz theory and FE model.

\subsection{Experimental determination of stiffness}

In addition to the stiffness characteristics values determined by Hertz and FE model, a linear model mockup bearing (LMMB) was fabricated to determine the stiffness characteristics experimentally. The raceways of length $150 \mathrm{~mm}$ were made from Medium Carbon Chromium Steel (AISI 4140) and through hardened to $50 \mathrm{HRc}$. The raceway grooves were ground to the required
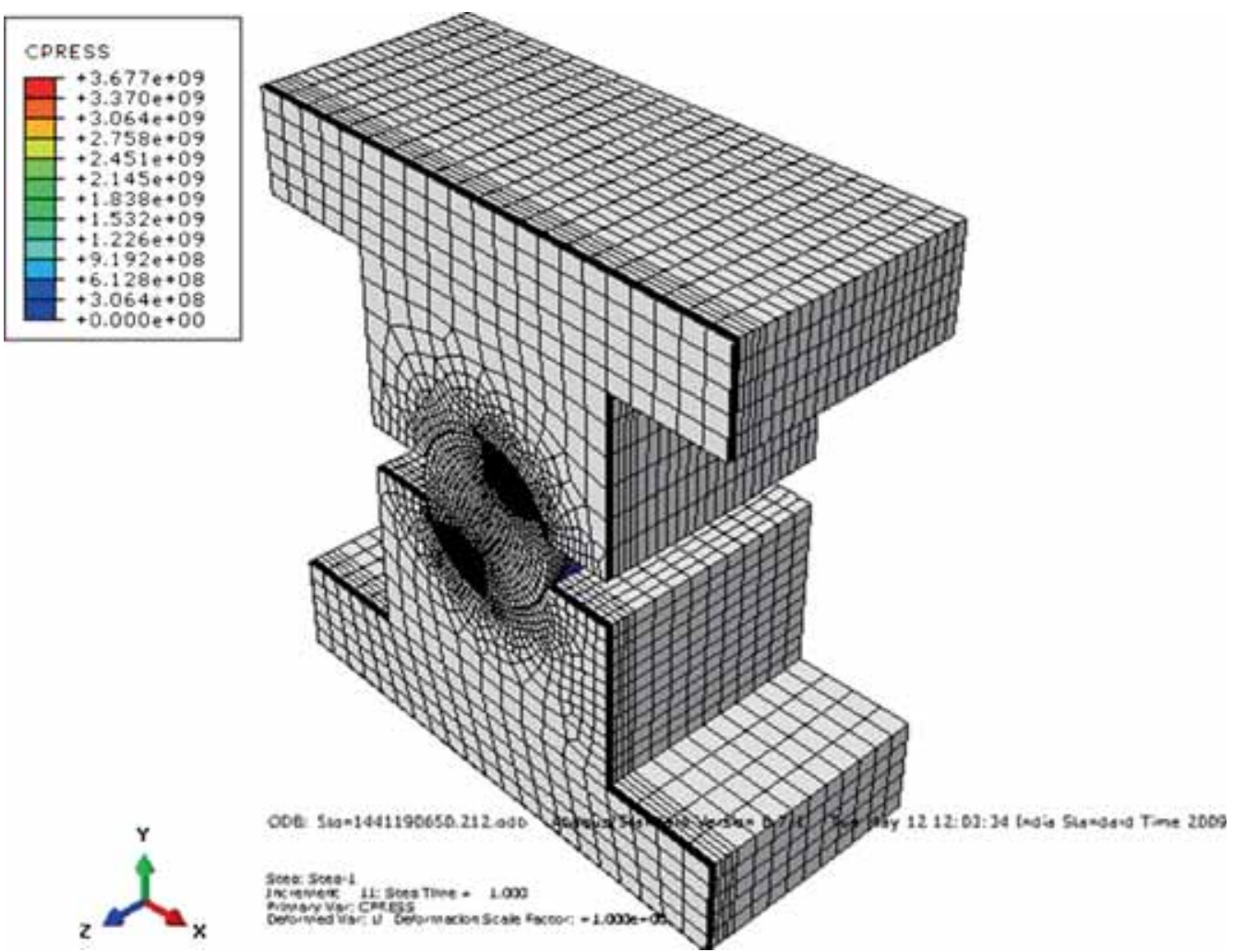

Figure 3. Bearing ball and race way contact model. 
radius of $16.51 \mathrm{~mm}$. In an actual ball bearing, the axis of the groove would be an arc of a circle about the axis of rotation. The rolling elements (balls of standard sizes $31.75 \mathrm{~mm}$ ) made of through hardened (62 HRc) high-Carbon Chromium Bearing Steel (AISI 52100) were purchased from commercial manufacturers. To study the load deformation characteristics of linear model bearing a special purpose test rig was fabricated and the setup is shown in figure 4 .

It was impossible to measure the deformation of the ball under load. Hence, LVDTs are used to measure the relative motion of the two races, that is, the deformation of balls and races combined as shown in figure 4. The two LVDTs are placed at opposite corners of the linear raceways. The tests were conducted on two sets of angular contact linear bearing mock up pieces by placing different number of balls between the raceways under loads varying from $200 \mathrm{~N}$ to $140 \mathrm{kN}$.

Figure 5 shows the plot between the load-deformation determined by experimental analysis, FEM, Hertz, and Manufacturers formula. The deviation of experimental results with analytical results is due to the variation in the hardness of the raceways and the ball, the dimensional variations in the ball diameter and deviation in the raceway curvature along the length of the cylindrical groove, the asymmetric in loading resulting in a non-uniform load distribution.

\section{Numerical model of large diameter bearing}

Simulation is carried out on an angular contact large diameter ball bearing using ABAQUS Standard FE codes. Abaqus Standard is a general-purpose finite element analyzer that employs implicit integration scheme. Geometrical and physical characteristics of the slewing ball bearing are given in figure 6. For the purpose of study, a 2 m model bearing with 70 rolling elements are modeled. The definition of a nonlinear connector is done in ABAQUS standard FE code. The behavior law is defined along a direction by a load-displacement table. The rings were meshed by "C3D8R: an 8-node linear brick, reduced integration, hourglass control" elements $(53,340$ elements for each ring) to preserve certain flexibility. The width of these elements at the contact

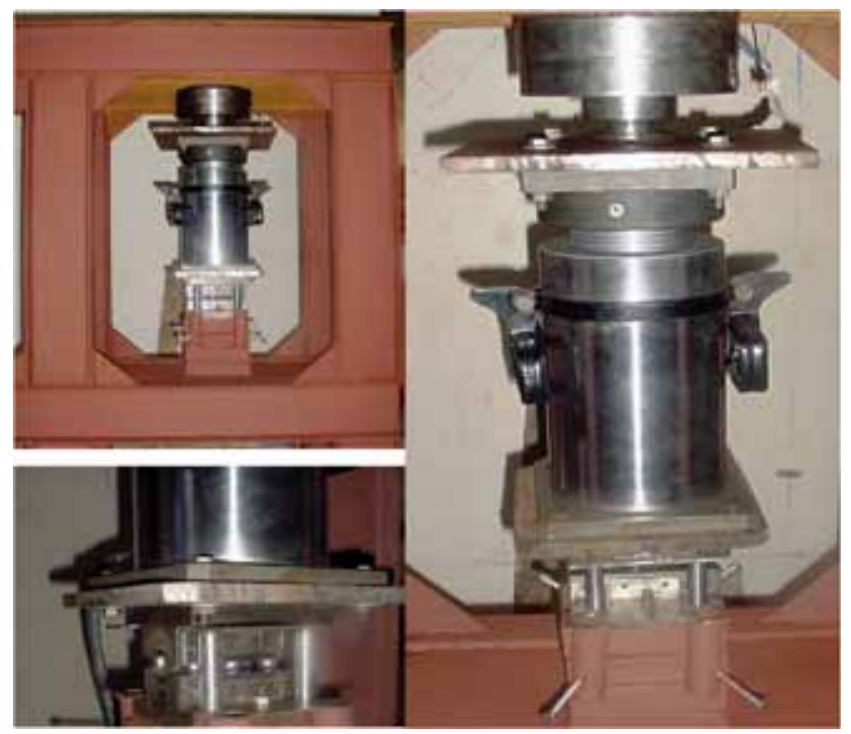

Figure 4. Experimental set up. 


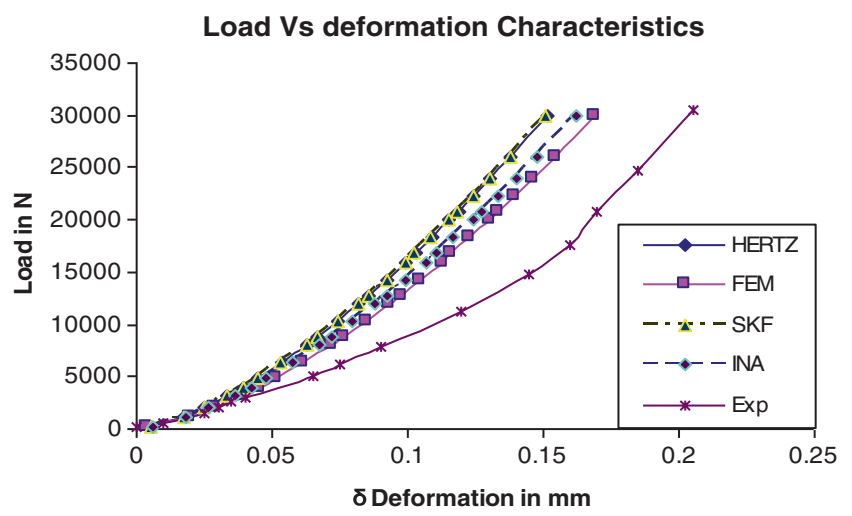

Figure 5. Plot between load and deformation.

zones, which are tied to the rigid shells, must equal the half-width of the contact ellipse defined by the Hertz theory. The rings are partitioned according to this criterion. In the analysis, lower face of the bottom ring is restrained in displacement, whereas external loading is applied on the top face of the top raceway. This configuration is similar to a slewing ring bearing fixed on a rigid support structure. For analysis, $180^{\circ}$ sector is modeled due to geometrical symmetry. In the first step, to study the behavior of the developed model a uniform axial load of $625 \mathrm{kN}$ is applied on the top face of the bearing ring.

The analysis shows a uniform load distribution on the $2 \mathrm{~m}$ model bearing and it is shown in figure 7. The figure shows that the loads are equally distributed for the applied uniform axial load (Starvin et al 2013). Hence the FE model is validated and can be used for the further analysis.

The contact load on individual rolling element found using FE method can also validated by comparing with simple analytical formula (Harris \& Kotzalas 2007) given below.

$$
F_{a}=Q Z \sin \beta
$$

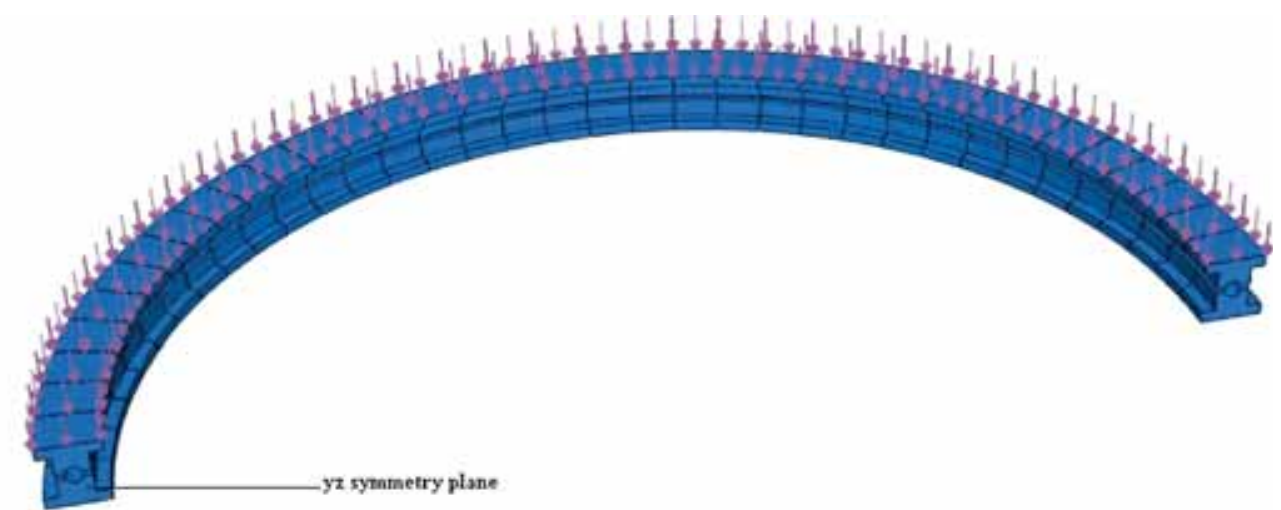

Figure 6. FE model of large diameter bearing (1/2 symmetry model). 
For the applied axial load the contact load evaluated using the above equation is $20,620 \mathrm{~N}$ which is well agree with the FE result obtained.

\section{Tolerance study}

The ball and roller bearings appear to be simple mechanisms, but their internal geometries are quite complex. The ability of the bearing to support the load depends on the ball and the raceways conformities ratio. In the determination of stresses and deflections, the relative conformities of balls with their contacting raceways are of vital interest. Manufacturing tolerances and method of production will affect the various dimensions in the bearing and their housings. Thus variations in the shape of the bearing and changes in the clearances can occur and such variations can significantly affect the performance of bearings of any size. However, with advanced manufacturing techniques and attention to structural design, together with the correct location of the bearing components, the shape of the profile in terms of similarity between rolling elements and raceways can be closely controlled with other dimensions.

The study has been carried out by allocating tolerance on balls and both balls and raceways. The dimensional variation on balls is taken as $25 \mu \mathrm{m}$ as per IS 2898-1976. The allocation of tolerances on balls is done by using Monte Carlo simulation techniques. Monte Carlo simulation is a proven, efficient technique that only requires a random number table or a random number generator on a computer. A random number is a mathematically selected value that is generated to conform to a probability distribution. This follows normal distribution of tolerances on ball dimension. For Monte Carlo simulation, a program was developed using Visual Basic and Microsoft Excel. More than two hundred trials are made. For each run mean, median, standard deviation, error, kurtosis and skewness are calculated. From the results to study the effect of dimensional variations, the run with minimum error and maximum error have been chosen to model the rolling elements.

The minimum and maximum percentage of error obtained from Monte Carlo simulation is $2.5 \%$ and $8 \%$ respectively. The distributions of ball diameter based on the maximum and minimum error are shown in figure 8 . All the balls in the model are not having the same dimension due to random allocation of tolerances based on the Monte Carlo simulation. The FE model is analyzed by applying a constant load of $625 \mathrm{kN}$ based on the specific applications. If all the balls are of uniform size, then the total load will be shared equally by all the balls. Since, the ball

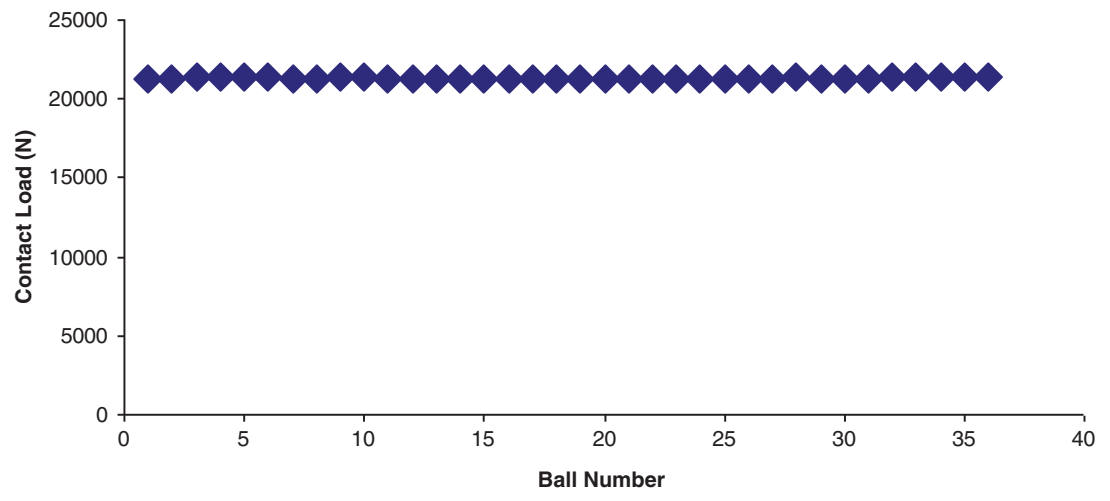

Figure 7. Uniform contact load distribution under axial loading. 

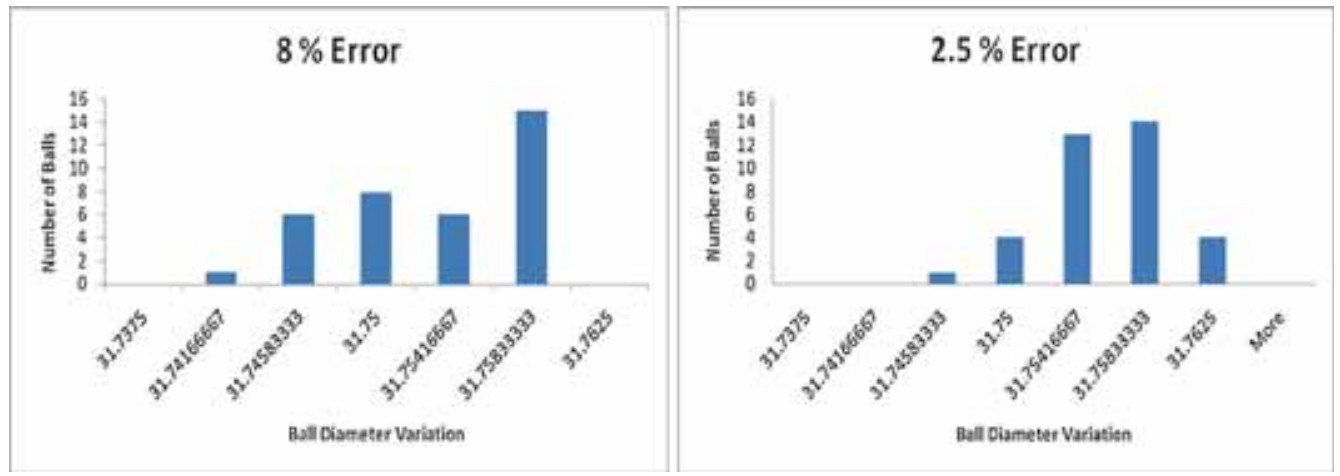

Figure 8. Ball diameter variation for $8 \%$ error and $2.5 \%$ error.

sizes are maintained at different levels to study the effect of tolerance on load carrying capacity; depending on the dimensions of the balls they are taking different loads (figure 9). Few balls are carrying more loads compared to other, due to the deviation of size of ball from mean value and the deformation of the raceway.

Furthermore, balls that are having higher dimensions will share more load initially, then the load will be shared by the other once it deforms. It is also observed that the contact load deviation is $\sim 11 \mathrm{kN}$ for $8 \%$ error, whereas $\sim 4 \mathrm{kN}$ in $2.5 \%$ error. This study clearly indicates that the deviation of load carried by the balls increases with increase in percentage of error in tolerance allocation.

The analysis has been extended by allocating the tolerance to both groove (raceway) and ball. For this study tolerance allocation with higher error (more variation as shown in figure 10) on ball is taken to study the worst case. The tolerance on the groove is given based on IT9 (for bearings) as per IS 286. Tolerances for a particular IT number have the same relative level of accuracy, but vary depending on the basic size. As per the IS standard, for $2 \mathrm{~m}$ diameter bearing size the groove tolerance limit is $40 \mu \mathrm{m}$. The tolerance values are allocated on the groove manually in addition to the ball diameter variation allocated as shown in figure 10. In modeling tolerance

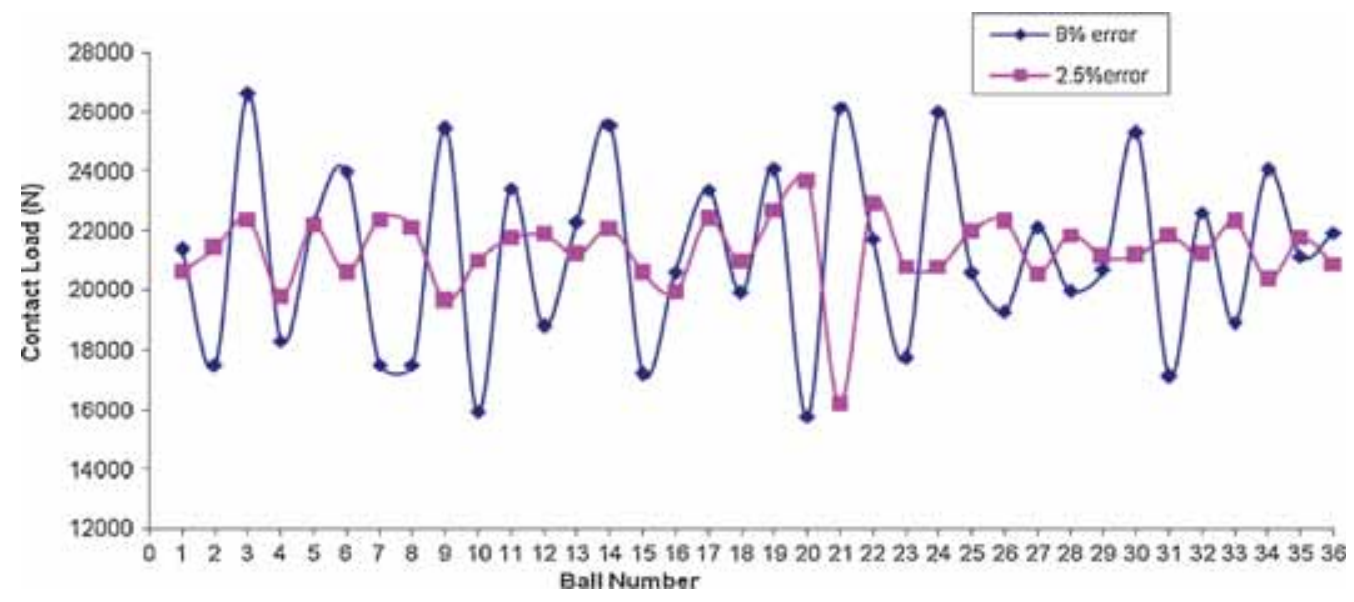

Figure 9. Effect of ball tolerance on load carrying capacity. 

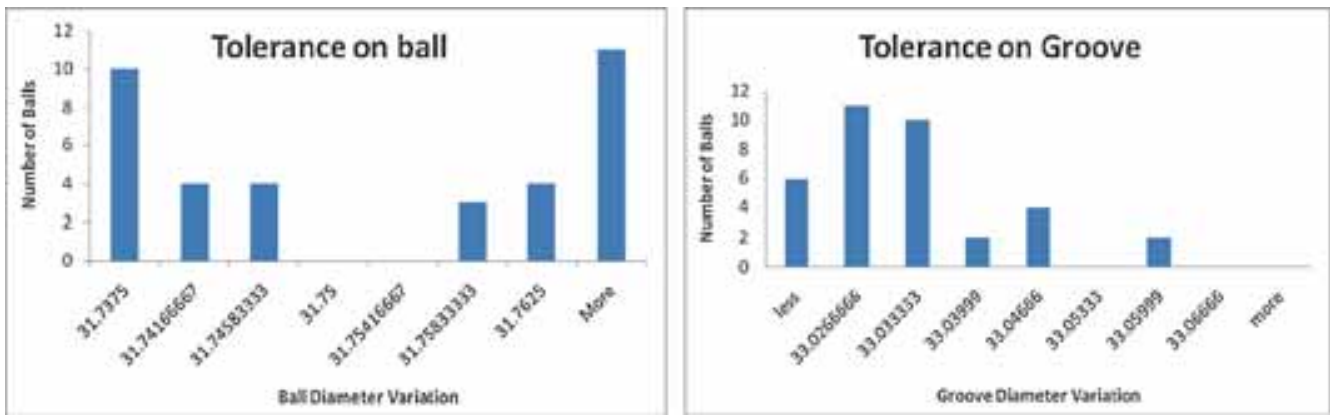

Figure 10. Diameter variation on ball and groove.

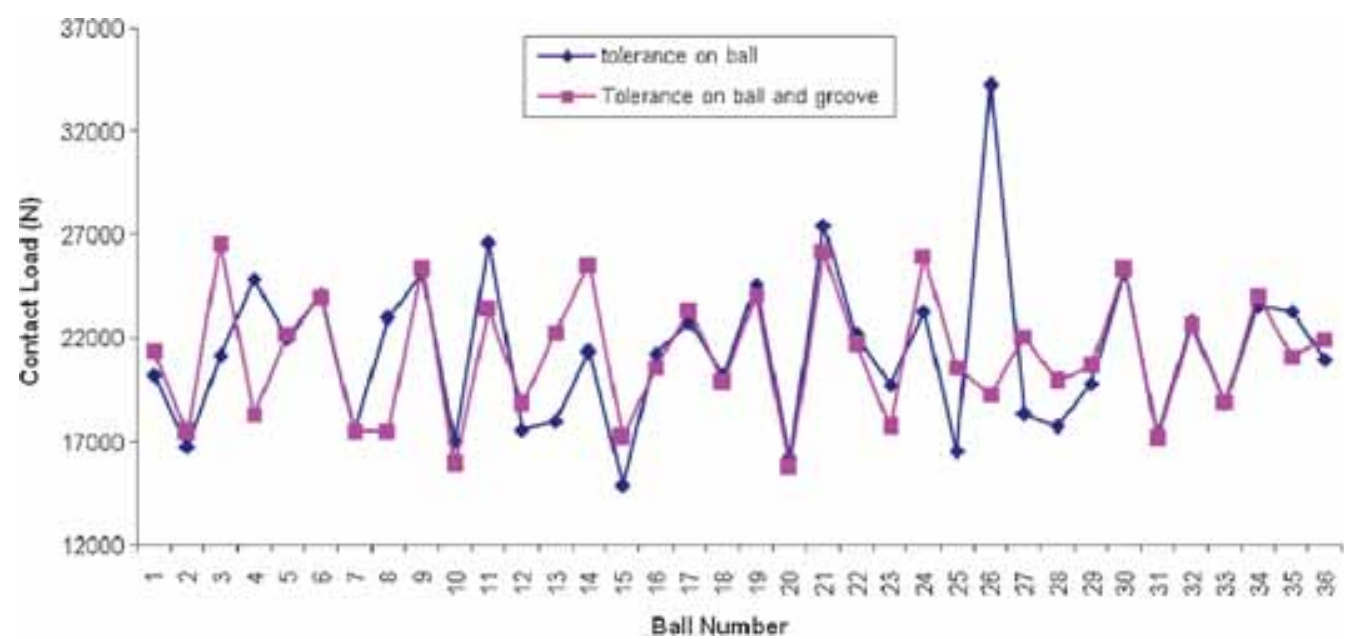

Figure 11. Comparison of ball tolerance and tolerance on ball and groove.

values both for the tolerance on the ball and groove were added to ball dimension and the balls are positioned randomly in the bearing raceways.

Since the study is made based on allocation of tolerance in groove manually, and it does not show any significant effect in sharing the loads, whereas the load allocation on the ball has been carried out based on Monte Carlo technique it shows a significant variation in sharing the total load acting on the bearing. It clearly indicates that the load shared by the balls is not equal and lesser number of balls is actively participating and subjected to heavy load due to more dimensional variation, and subsequently it may lead to failure of the bearings. Hence, for conservative design, it is recommended to assign the tolerance on ball and groove with minimum dimensional variation (figure 11).

\section{Conclusion}

In the present work, stiffness of the rolling element of the large diameter bearing had been determined using Hertz theory. The determined value of stiffness was compared with the experimentally determined value and the value predicted using finite element analysis. Using the determined value of stiffness, the large diameter bearing was modeled and analyzed under two 
different conditions. From the results of finite element analysis, it is identified that an increase in tolerance leads to more variation in the load carrying capacity of large diameter bearing. Hence it was suggested that for conservative design of large diameter bearings, tolerance has to be assigned on both ball and groove with minimum dimensional error.

\section{Acknowledgement}

The authors thank Board of Research in Nuclear Sciences, Mumbai, which provided financial support for carrying out this research work at Structural Mechanics Laboratory, Indira Gandhi Centre for Atomic Research, Kalpakkam, India.

\section{Nomenclature}

a semi-major axis of the projected contact, $\mathrm{mm}$

b semi-minor axis of the projected contact, $\mathrm{mm}$

S osculation ratio

$\mathrm{D}_{\mathrm{w}} \quad$ ball diameter, $\mathrm{mm}$

$\beta, \quad$ contact angle, $\mathrm{rad},{ }^{\circ}$

$\mathrm{D}_{\text {mean }} \quad$ mean diameter of bearing in $\mathrm{mm}$

Q ball-raceway normal load, $\mathrm{N}$

$\mathrm{P}_{\max } \quad$ maximum contact pressure $\mathrm{N} / \mathrm{mm}^{2}$

$\mathrm{P}_{\text {mean }} \quad$ mean contact pressure $\mathrm{N} / \mathrm{mm}^{2}$

$\delta \quad$ deflection or contact deformation, $\mathrm{mm}$

$\mathrm{f}_{\mathrm{i}} \quad$ inner race conformity

$\mathrm{f}_{\mathrm{o}} \quad$ outer race conformity

\section{References}

ABAQUS, Theory Manual 6.7., ABAQUS Inc. http://www.abaqus.com

Alain Daidié, Zouhair Chaib and Antoine Ghosn 2008 3D simplified finite elements analysis of load and contact angle in a slewing ball bearing. J. Mech. Des. 130: 082601-1-8

Antoine J F, Abba G and Molinari A 2006 A new proposal for explicit angle calculation in angular contact bearing. ASME J. Tribol. 128(2): 468-478

Goncz P, Drobne M and Glodez S 2013 Computational model for determination of dynamic load capacity of large three- row roller slewing bearings. Eng. Failure Anal. 32: 44-53

Harris T A and Kotzalas M N 2007 Rolling bearing analysis. 5th Ed. Boca Raton (FL): CRC/Taylor \& Francis

Hong-Chao Zhang 1997 Advanced tolerancing techniques. John Wiley and Sons, Inc:587

Houpert L 2001 An engineering approach to Hertzian contact elasticity - Part I and II. ASME J. Tribol. 123: $582-588$

INA, Wälzlager Schaeffler KG, Industriestra_e 1-3, 91074 Herzogenaurach, Deutschland, http://www.ina. de

Jose Ignacio Amasorrain, Xabier Sagartzazu and Jorge Damián 2003 Load distribution in a four contactpoint slewing bearing. Mech. Mach. Theory 38: 479-496

Liao N T and Lin J F 2001 A new method for the analysis of deformation and load in a ball bearing with variable contact angle. ASME J. Mech. Des. 123(2): 304-312

Ngoi B K A, Lim B H and Ang P S 2000 Nexus method for stack analysis of geometric dimensioning and tolerancing problems. Int. J. Production Res. 38: 21-37

SKF, SE-415 50 Göteborg, Sweden, Company Reg. No. 556007-3495, http://www.skf.com 
Smolnicki T 1999 Nonlinear models of the system: Track-ball-track for determining pressure distribution in a largesize rolling bearing. Przeglad Mechaniczny 58(5-6): 16-20

Smolnicki T and Rusiniski E 2007 Super element-based modeling of load distribution in large-size slewing ring bearings. J. Mech. Des. 129: 459-463

Starvin M S, Babu S, Aithal Sriramachandra, Manisekar K and Chellapandi P 2013 Finite element simulation of nonlinear deformation behaviour in large diameter angular contact thrust bearing. Scientific Res. Essays 8: 128-138

Zupan S and Prebil I 2001 Carrying angle and carrying capacity of a large single row ball Bearing as a function of geometry parameters of the rolling contact and supporting structure stiffness. Mech. Mach. Theory 36: 1087-1103 